\title{
Economical Smart Farming
}

\author{
Mr Shine.H, Logeswari.J, Divyalakshmi.A, Asha.E
}

\begin{abstract}
Cultivating and agribusiness is the premise of human life which gives nourishment, beats, and other crude materials. The significant consideration in horticulture is soil the board for upgrading crop efficiency is on the upkeep and improvement of dynamic soil parameters. The earthbound confinements, populace stresses and the decrease of customary soil the executives strategies have coordinated to disintegration in the richness of the dirt in creating nations like India. The soundness of yield is a significant component in the profoundly beneficial arrangement of present day agribusiness. The Wild system, it is conceivable to lessen defer and improve throughput for end mile availability. The mist figuring arrangement makes a move with lesser deferral and spares data transmission in the system. The economy of a creating nation for the most part relies upon agribusiness and homesteads in rustic regions and applying conventional methodologies isn't adequate. The proposed framework concentrated on executing an effective AI calculation which is only the blend of more than one ML calculation to shape a cross breed arrange in profound learning. Half breed mix of KNN and SVM Model is created. K-closest neighbor is the semi-managed model and it will be increasingly powerful in parameter level characterization. At last the kind of harvest will be shown.
\end{abstract}

Keywords : Crop yeild, Data processing, Machine learning, self-organized mapping.

\section{INTRODUCTION}

Anthropogenic environmental change will influence the rural area more legitimately than numerous others on account of its immediate reliance on climate. The nature and size of these effects depends both on the advancement of the atmosphere framework, just as the connection between crop yields and climate. This paper centers around the last mentioned-yield forecast from climate. Exact models mapping climate to edit yields are significant for anticipating effects on agribusiness, yet in addition for anticipating the effect of environmental

Revised Manuscript Received on April 11, 2020.

* Correspondence Author

Mr Shine*, H is working as a assistant professor in Computer Science and Engineering in Jeppiaar Institute of technology, Sriperumpudur, Chennai, India, PH- 98413 46080, E-mail: shineh@jeppiaarinstitute.org.

Logeswari.J, is currently pursuing Bachelors of degree in Computer science and Engineering in Jeppiaar Institute of Technology, Sriperumpudur, Chennai, India, PH-9840872592, E-mail: ammuloka.official@gmail.com.

Divyalakshmi.A, is currently pursuing Bachelors of degree in Computer science and Engineering in Jeppiaar Institute Of Technology, Sriperumpudur, Chennai, India, PH-9688448705 E-mail: lakshmi.div99@gmail.com.

Asha.E, is currently pursuing Bachelors of degree in Computer science and Engineering in Jeppiaar Institute Of Technology, Sriperumpudur, Chennai, India, PH-7010526611, E-mail: ashaelumalai2599@gmail.com.

(C) The Authors. Published by Blue Eyes Intelligence Engineering and Sciences Publication (BEIESP). This is an open access article under the CC BY-NC-ND license (http://creativecommons.org/licenses/by-nc-nd/4.0/) change on connected financial and natural results, and thusly for moderation and adjustment arrangement. In equal, AI (ML) systems have progressed extensively in the course of recent decades. ML is rationally particular from quite a bit of old style measurements, to a great extent since its objectives are extraordinary - it is to a great extent concentrated on expectation of results, instead of induction into the idea of the robotic procedures creating those results. (We center around regulated ML-utilized for expectation-instead of unsupervised ML, which is utilized to find structure in unlabeled information.)

\section{MOTIVATION}

\section{A. Scope}

The scope of this project is to predict the type of crops for particular kind of soil.

\section{B. Objective}

1. No wastage of crops by yielding wrong kind.

2. Reduces the work time on soil.

3. Engage youngsters into the agriculture field.

4. Predicts the applicable crop for the soil type.

\section{METHODOLOGY}

The methodology design is based on the data preprocessing which is used to read the soil dataset, prepare it to make a readable format, labialize the values, plot the required histograms for analysis etc ,KNN algorithm used to design a K-Nearest Neighbor algorithm which is a semi-supervised model, get the sample data, training data from the database and finally predict the group it fit perfectly. The class values are helpful to get the first level of prediction values and integration \& hybrid classification model which is used to implement a hybrid classification model to determine the soil nutrients present in particular location and accuracy for the same. The predicted values are geographically plotted,thus the input parameters are potassium content, $\mathrm{PH}$ content, humus content and calcium content of the soil.

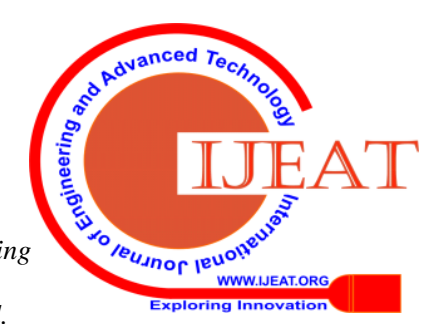



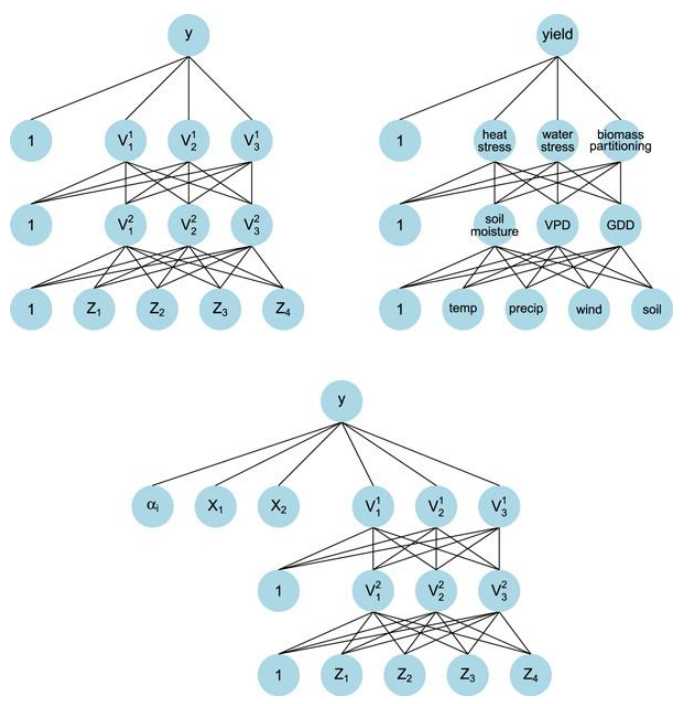

\section{A. Data visualization}

This module is utilized to peruse the tried soil dataset observed from the lab which contains the mineral substance of soil under test.

The module read the dataset document, measure the information present into the record, the length of the datafile Standardize the information by expelling the undesirable characters present in the document. By filtering the NAN(not a number) and INF(infinite esteem)

\section{B. Deep learning-Pattern Net}

This module is utilized to make an exceptional Deep Pattern-Net utilizing Baysien Regularization calculation in which the info example of Soil parameters are stacked into the calculation after component extraction through Self organized mapping algorithm.

\section{Integration and Crop yield Decision}

This module is utilized to coordinate the sub-modules of the preprocessing and highlight extraction with Deep learning pattern net to which yield the Crop yielding soil present in the area and what kind of harvest will be suggested. The proposed design is execution estimated with accuracy, precision and recall

\section{WORKING}

For this project the working process has been divided into three different phases to carry the entire.

\section{A. Data Gathering Phase}

This phase deals with acquiring the data of the soil which consists of parameters like calcium content, potassium content, humus content and $\mathrm{PH}$ content. The data will be collected from the lab after the tests of the soil. So, the information regarding the soil will be stored as a dataset and thus the data will be trained where the undefined values will be filtered. Finally a proper data set will be obtained.

\section{B. Coding Phase}

- Here the code for the device is written. The algorithm used here is Hybrid Pattern Net ,which trains the dataset and with help of the parameters the calculation of component extraction through self organized mapping is obtained.

\section{Validation Phase}

This phase includes the values of parameters which is fed as input into the calculation to obtain the result. The input parameters are potassium content, $\mathrm{PH}$ content, humus content and calcium content of the soil. Here when the program is run ,it delivers the results in histogram where the clear vision of the dataset can be seen. The validation of dataset is trained through program and resulted in plots.
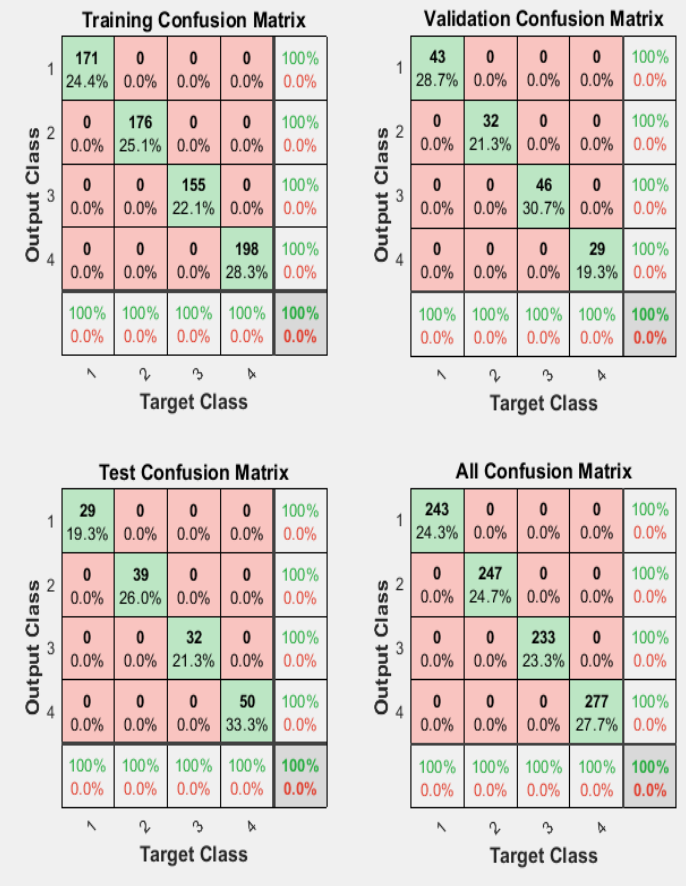

\section{Result Phase}

Once the input parameters are fed into the program, it runs and as the result it shows the user with the type of crop for that particular soil and it also shows the location of that crop's native.

\section{ARCHITECTURE AND WORKFLOW}

\section{A. Design work}

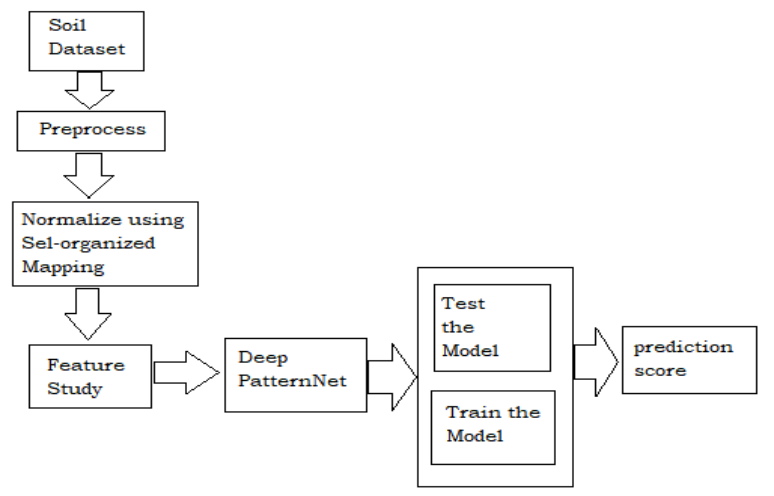

The above figure explains the flow of process where at first the soil dataset is collected and stored , then it is preprocessed and normalized using self organized mapping algorithm. After normalizing the data,

Published By: Blue Eyes Intelligence Engineering \& Sciences Publication

(C) Copyright: All rights reserved.

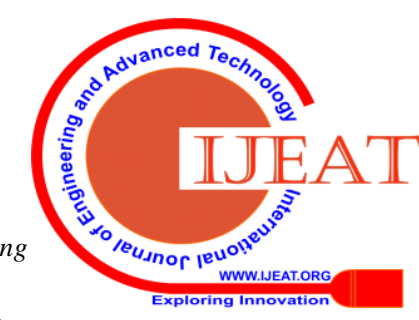


Hybrid Pattern Net is used where it formulates the calculation of component extraction for soil. Thus the model is trained and resulted in histograms like regression plot,error histogram ,etc,. At last the kind of crop will be displayed with its native location.

\section{RESULT AND DISCUSSION}

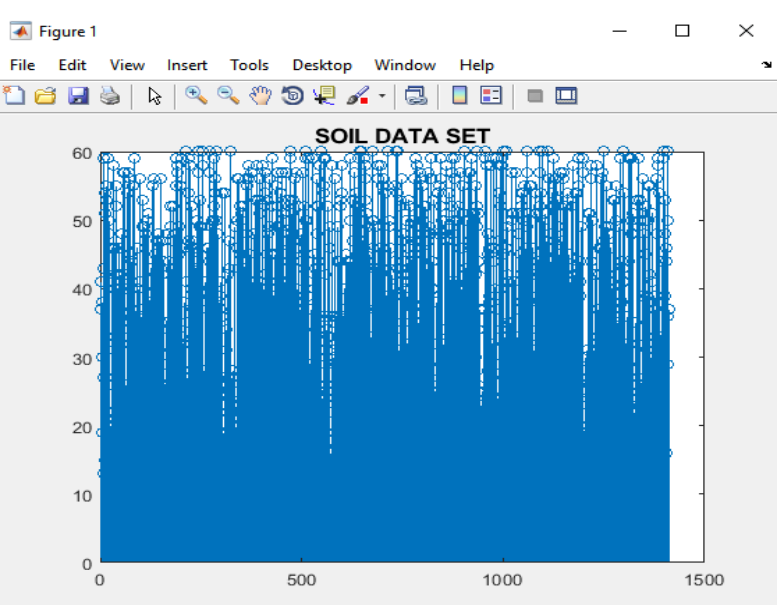

Fig 1 : Regression plot

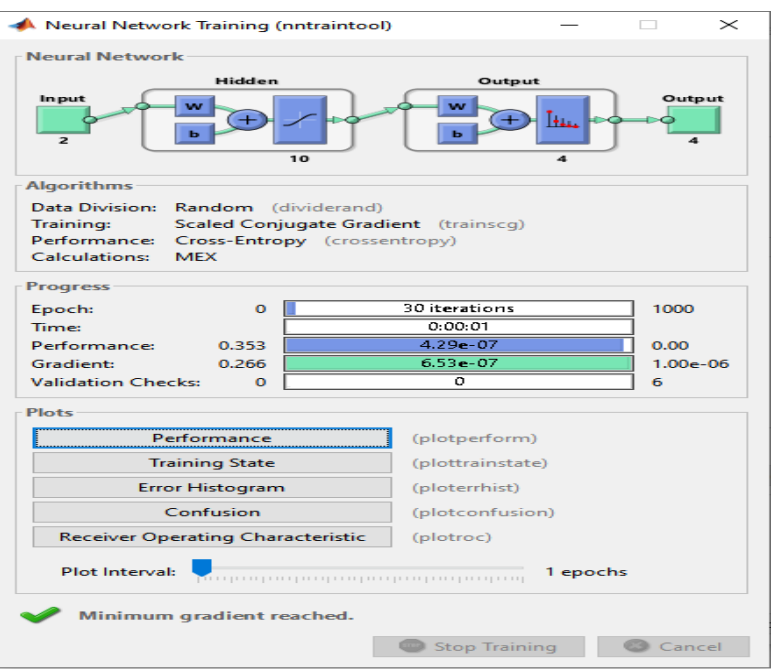

Fig 2 :Neural network training

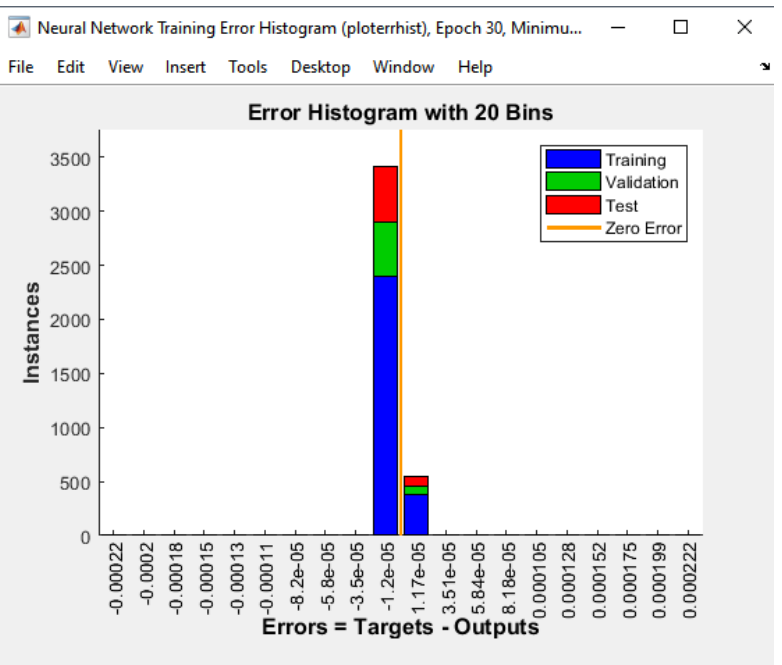

Fig 3 : Error histogram

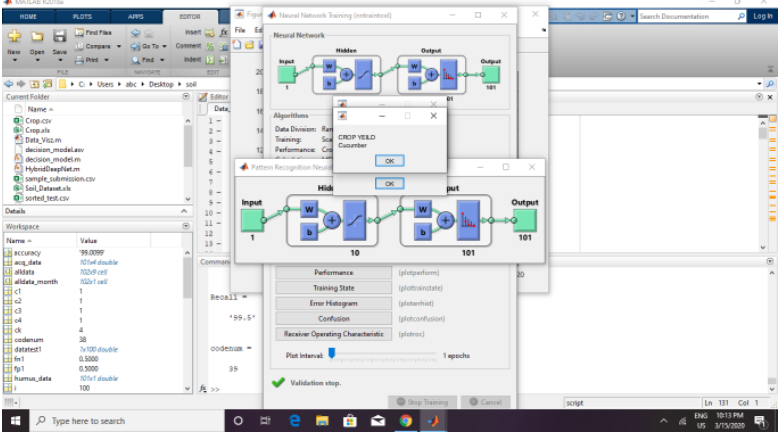

Fig 4: Crop type

\section{FUTURE SCOPE}

Currently we are performing the process with neural network and hybrid pattern net algorithm, this can be futher recreated using image processing where with the image of the soil the device would suggest the appropriate kind of crop for the particular soil type. By sensing the image of the soil in image processing it may suggest you the best kind of crop.This helps in time efficiency and wastage of crops.

\section{CONCLUSION}

Due to the device's cost and time efficiency, easy interactivity with the users it has reduced the workload of the farmers. It consumes less time in investing time period for deciding the type of crop to yield. This device helps in encouraging youngsters to get in agriculture field which easily suggests you the best crop to yield so nobody has a chance of spending time on wrong kind of crops and there would be no wastage of crops,time and money.

\section{REFERENCES}

1. Burney J, Ramanathan V. Recent climate and air pollution impacts on Indian agriculture. Proceedings of the National Academy of Sciences of the United States of America. 2014;111(46):16319-16324.

2. Amandeep et al., "Smart farming using IOT," 2017 8th IEEE Annual Information Technology, Electronics and Mobile Communication Conference (IEMCON), Vancouver, BC, 2017.

3. Arnaud S. R. M. Ahouandjinou, Probus M. A. F. Kiki, Kokou Assogba, "Smart Environment Monitoring System by Using Sensors Ultrasonic Detection of Farm Pests", IEEE 978-1-5386-0706-0/17/\$31.00, 2017.

4. Maherin Mizan Maha , Sraboni Bhuiyan and Md Masuduzzaman, "Smart Board for Precision Farming Using Wireless Sensor Network", 2019 International Conference on Robotics,Electrical and Signal Processing Techniques (ICREST).

5. L. Kloosterman, K. Mager, "Pheromone trap", Chapter: Pest control in food businesses: an introduction, Hygiene in Food Processing (Second Edition), 2014

6. K Srinivasa Rao, N Nagendra, "Automatic Watering of an Expressional Gardening System", International Journal of Electronics, Electrical and Computational System, ISSN 2348-117X, Vol 6, Issue 11, November 2017

7. S. Pudumalar, E. Ramanujam, R. H. Rajashree, C. Kavya, T. Kiruthika and J. Nisha, "Crop recommendation system for precision agriculture,"2016 Eighth International Conference on Advanced Computing (ICoAC), Chennai, 2017, pp. 32-36.

8. Anand Nayyar, Er. Vikram Puri, "Smart Farming: IoT Based Smart Sensors Agriculture Stick for Live Temprature and Moisture Monitoring using Arduino, Cloud Computing \& Solar Technology"

9. Hariharr C Punjabi, Sanket Agarwal, Vivek Khithani and Venkatesh Muddaliar, "Smart Farming using IOT" [online], International Journal of Electronics and Communication Engineering and Technology (IJECET) Volume 8, February 2017.

Published By:

Blue Eyes Intelligence Engineering \& Sciences Publication

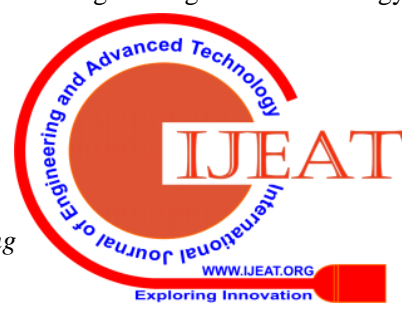


10. ] Zamora-Izquierdo, M. A., Santa, J., Martínez, J. A., Martínez, V., \& Skarmeta, A. F. (2019). Smart farming IoT platform based on edge and cloud computing. Biosystems engineering, 177, 4-17.

11. Liu, X., Zhang, C., Liu, P., Yan, M., Wang, B., Zhang, J., \& Higgs, R. (2018). Application of Temperature Prediction Based on Neural Network in Intrusion Detection of IoT. Security and Communication Networks, 2018.

12. Kamilaris, A., Kartakoullis, A., \& Prenafeta-Boldú, F. X. (2017). A review on the practice of big data analysis in agriculture. Computers and Electronics in Agriculture, 143, 23-37.

13. Mehra, M., Saxena, S., Sankaranarayanan, S., Tom, R. J., \& Veeramanikandan, M. (2018). IoT based hydroponics system using Deep Neural Networks. Computers and electronics in agriculture, 155, 473-486.

\section{AUTHORS PROFILE}

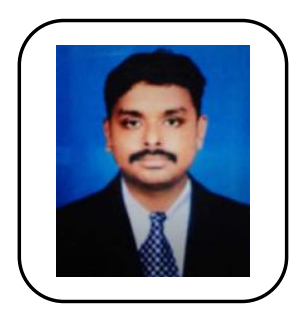

Mr Shine.H was born in Chennai, Tamilnadu in 1985. He is currently working as a Assistant Professor of Computer Science and Engineering at Jeppiaar Institute of Technology, Kunnam, Suguvarchatram. Having 6 years of Teaching Experience currently. His area of interest is programming languages, data science and Internet of Things. E-mail: shineh@jeppiaarinstitute.org .

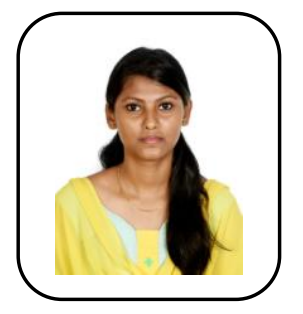

Logeswari.J was born in Chennai, Tamilnadu in 1999. She is currently pursuing Bachelors of degree in Computer science and Engineering in Jeppiaar Institute Of Technology, Sriperumpudur, Chennai, India. She has Participated and Presented a paper in the International Conference on Introduction to Data science. Active member in Computer Society of India E-mail: ammuloka.official@gmail.com@gmail.com

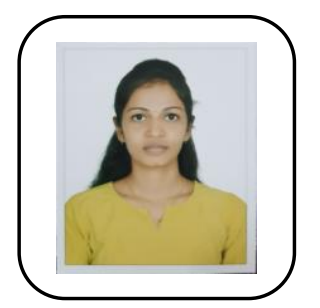

Divyalakshmi.A was born in Cheyyar, Tamilnadu in 1999. She is currently pursuing Bachelors of degree in Computer science and Engineering in Jeppiaar Institute Of Technology, Sriperumpudur, Chennai, India. Active member in Computer Society of India E-mail: lakshmi.div99@gmail.com.

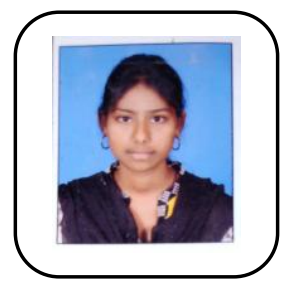

Asha,E was born in Kanchipuram,Tamilnadu in 1999.She is currently pursuing Bachelors of degree inComputer Scirnce and Engineering in Jeppiaar Institute of Technology, Sriperumpudur, Chennai, India. E-mail: ashaelumalai2599@gmail.com

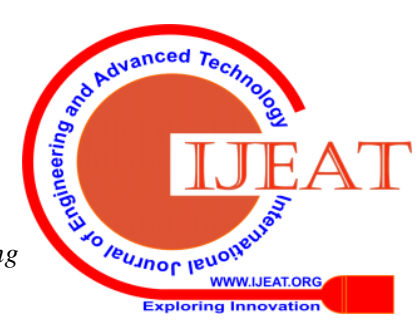

